\title{
Kajian Efektifitas Penggunaan Fasilitas Parkir pada Terminal Angkutan Barang Pulo Gebang Jakarta Timur
}

\author{
Rudi Agus Widono, Nahry \\ Program Studi Teknik Sipil, Fakultas Teknik, Universitas Indonesia \\ Email:agus.taboeti@yahoo.com
}

\begin{abstract}
Economy development in Jakarta City is accompanied by increasing transportation activity, such as loading and unloading at harbor. Heavy vehicle working in Tanjung Priok Harbor needs parking area. One of parking area is Pulo Gebang Freight Terminal. The parking area in this terminal is often full and requires development. As a result double parking vehicles cannot be avoided in this area. Based on this condition, this research is aimed to assess Pulo Gebang Freight Terminal as a parking facility and to improve its utility. From 6 days observation, the parking characteristics value in terminal are obtained, such as Turn Over of 0,053-0,101, Parking Index of 60,9\%-105,5\%, Parking Activity Index (PAI) of 0,54-0,81, and V/C Ratio of 45\%-59\%. These parameters show that the terminal always full and has been utilized effectively. However, the terminal still has some room for development. The development can be obtained by analyzing some scenario that can be implemented in the parking area. These include broken vehicle restriction, paves the land behind the terminal, operates the terminal's second gate, and changes the vehicle receiving system from renting system. By these scenarios, the static capacity of the terminal can be increased up to $30,43 \%$.
\end{abstract}

Keywords: parking, effectiveness, freight terminal.

\section{Abstrak}

Berkembangnya perekonomian kota Jakarta diikuti oleh meningkatnya kegiatan logistik dan transportasi, dimana salah satunya ditunjukkan oleh meningkatnya kegiatan bongkar muat di pelabuhan. Kendaraan angkutan barang yang beraktifitas di pelabuhan Tanjung Priok membutuhkan tempat parkir, salah satunya di Terminal Angkutan Barang (TAB) Pulo Gebang. Saat ini utilisasi fasilitas parkir di terminal ini pada waktu-waktu tertentu cukup tinggi dan tampak memerlukan pengembangan, hal ini terlihat dari adanya parkir ganda. Berdasarkan kondisi ini, penelitian ini ditujukan untuk menganalisa efektifitas penggunaan TAB Pulo Gebang saat ini sebagai fasilitas parkir dan mengkaji potensi perbaikan utilisasinya. Dari pengamatan selama 6 hari diperoleh nilai rata-rata karakteristik parkir berupa Turn Over sebesar 0,0530,101, Indeks Parkir 60,9\%-105,5\%, Indeks Aktifitas Parkir (IAP) 0,54-0,81, dan V/C ratio 45\%$\mathbf{5 9 \%}$. Parameter-paramter ini menunjukkan bahwa terminal selalu dalam keadaan penuh dan terutilisasi dengan cukup efektif. Walaupun demikian, terminal masih memiliki potensi untuk dikembangkan. Potensi dilihat dengan menganalisa beberapa skenario yang mungkin diimplementasikan yaitu melarang keberadaan kendaraan tidak layak jalan, memperkeras lahan di belakang terminal, mengoperasikan pintu kedua terminal, dan mengubah sistem penerimaan kendaraan menjadi bukan sistem sewa. Dengan skenario-skenario ini, kapasitas statis terminal dapat ditingkatkan hingga $30,43 \%$.

Kata Kunci: parking, efektifitas, terminal angkutan barang.

\section{Pendahuluan}

Pesatnya pertumbuhan ekonomi yang diikuti dengan peningkatan aktifitas sosial ekonomi menimbulkan perkembangan kota yang semakin cepat, termasuk kota Jakarta. Salah satu pusat aktivitas perekonomian kota Jakarta adalah kegiatan logistik di pelabuhan Tanjung Priok seperti bongkar muat barang. Kendaraan yang melakukan

Jurnal APLIKASI: Media Informasi \& Komunikasi Aplikasi Teknik Sipil Terkini Halaman 43 
bongkar muat membutuhkan lahan parkir di titik asal dan tujuan perjalanan mereka. Kegiatan ini didukung oleh keberadaan beberapa terminal angkutan barang, salah satunya Terminal Angkutan Barang (TAB) Pulo Gebang.

TAB Pulo Gebang saat ini, berfungsi hanya sebagai tempat pemberhentian sementara bagi kendaraan angkutan barang agar tidak menggunakan daerah tepi jalan raya sebagai tempat parkir mereka. Kendaraan yang memanfaatkan fasilitas TAB Pulo Gebang hanya boleh menitipkan kendaraan mereka saja dengan tidak melakukan aktifitas apapun seperti bongkar muat barang dan bongkar pasang kendaraan. Terminal ini aktif 24 jam terlepas dari apakah ada aktifitas kedatangan/kepergian kendaraan ke/dari terminal.

Saat ini, di TAB Pulo Gebang terlihat ada beberapa kendaraan yang posisi parkirnya menutup posisi parkir kendaraan lain (double parking) sehingga menghalangi manuver keluar masuk kendaraan tersebut. Disamping itu, terlihat kendaraan rusak seperti bus dan kendaraan roda dua tidak layak jalan yang ditampung sementara di terminal. Hal ini dapat mengurangi kapasitas parkir terminal dan kecepatan manuver kendaraan masuk keluar. Berdasarkan pengamatan ini, diperlukan kajian untuk untuk menganalisa efektifitas pengaturan parkir saat ini serta mengkaji beberapa skenario sebagai upaya perbaikan yang mungkin dapat dilakukan pada fasilitas parkir di TAB Pulo Gebang untuk meningkatkan utilisasinya.

\section{Metodologi}

Menurut Undang-Undang Nomor 14 Tahun 1992 Tentang Lalu Lintas dan Angkutan Jalan pasal 1 ayat 5, terminal adalah prasarana transportasi jalan untuk keperluan memuat dan menurunkan orang dan/atau barang serta mengatur kedatangan dan pemberangkatan kendaraan umum, yang merupakan salah satu wujud simpul jaringan transportasi.

Karakteristik parkir serta tingkat gangguan aktivitas parkir terhadap arus lalu lintas di sekitarnya digambarkan dalam bentuk parameter-parameter berikut ini:

1. Akumulasi Parkir, merupakan jumlah kendaraan yang diparkir di suatu tempat pada waktu tertentu, dan dapat dibagi sesuai dengan kategori jenis dan maksud perjalanan (Oppenlander \& Box, 1976).

Akumulasi $=k_{r n}-K_{\hbar}+\times \ldots \ldots \ldots \ldots \ldots[1]$

Dimana:

$K_{m}=$ kendaraan masuk

$K_{k}=$ kendaraan keluar

$x=$ total kendaraan yang sudah parkir

2. Volume Parkir, menyatakan jumlah kendaraan yang termasuk dalam beban parkir yaitu jumlah kendaraan per periode waktu tertentu, biasanya per hari (Zakaria, 2010).

$V_{p}=E_{i}+\times$

Dimana:

$V_{p}=$ Volume Parkir (kendaraan/hari)

$E_{i}=$ Entry (kendaraan yang masuk lokasi parkir)

Halaman 44 Jurnal APLIKASI: Media Informasi \& Komunikasi Aplikasi Teknik Sipil Terkini 
3. Tingkat Pergantian Parkir (Parking

Turn Over, TR), menunjukkan tingkat penggunaan ruang parkir. Turn Over diperoleh dari pembagian antara jumlah total kendaran yang parkir dengan jumlah petak parkir yang tersedia selama waktu pengamatan (Oppenlander \& Box, 1976).

$T R=\left(\frac{N_{t}}{s \times T_{s}}\right)$

Dimana:

$\mathrm{TR}=$ angka pergantian parkir (kendaraan/SRP/jam).

$\mathrm{S}=$ jumlah total stall/petak resmi (SRP).

$T_{x}$ = lamanya periode survai (jam).

$N_{t}=$ jumlah total kendaraan pada saat dilaksanakan survai (kendaraan).

4. Indeks Parkir, adalah suatu ukuran untuk menentukan besar pemakaian parkir dan dinyatakan dalam persentase (Priadi, 2001).

Indeks

parkir $=\frac{\text { Akwumulasi Parhitr }}{\text { Ruarg parkir yung tersedia }} \times 100 \% \ldots . . .[4]$

5. Durasi parkir, adalah lamanya suatu kendaraan parkir pada suatu area parkir (Priadi, 2001).

Durasi $=T_{\mathrm{i}}-T_{0}$

Dimana:

$T_{\mathrm{i}}=$ waktu kendaraan masuk

$T_{0}=$ waktu kendaraan keluar

6. Indeks Aktifitas Parkir (IAP), adalah suatu ukuran/nilai untuk menyatakan tingkat kesibukan/aktifitas parkir di suatu area parkir tertentu (Swanson, 1994).

$\mathrm{IAP}=\frac{\text { Turrover rats }}{\text { Rerata Durazi parkir }} \times$ Indeks Parkir $[6]$
7. Kapasitas Statis Terminal, adalah jumlah ruang parkir yang tesedia pada suatu lahan parkir (Tamin, 2000).

8. Kapasitas Dinamis Terminal, tergantung pada besarnya rata-rata durasi atau lamanya kendaraan parkir (Tamin, 2000).

Kap. dinamis Parkir $=\begin{gathered}\text { Rap. atutis parkir } \times 24 \text { jam } \\ \text { Durasi Parkir }\end{gathered} \ldots[7]$

9. Tingkat Pelayanan Terminal, dapat dinilai dengan menggunakan rasio Volume dengan Capacity (V/C ratio). Rasio ini adalah perbandingan antara volume kendaraan yang masuk terminal dengan jumlah maksimal kendaraan yang dapat masuk terminal dalam kondisi normal.

$\mathrm{V} / \mathrm{C}$ ratio $=\frac{\text { wolume parkir }}{\text { kapositas dinamis }}$

10. Tundaan di persimpangan adalah total waktu hambatan rata-rata yang dialami oleh kendaraan sewaktu melewati persimpangan. Tundaan juga dapat menentukan Indeks Tingkat Pelayanan (ITP) suatu persimpangan (Tamin, 2000). Nilai Tundaan dalam penelitian ini digunakan untuk melihat pengaruh aktivitas keluar masuknya kendaraan $\mathrm{ke} /$ dari terminal terhadap arus lalu lintas yang melewati ruas jalan di depan terminal.

Diagram alir penelitian ditunjukkan oleh gambar 1. Pengumpulan data primer dilaksanakan pada hari Rabu 30 Oktober 2013 pukul 13.00 hingga Senin 4 November 2013 pukul 11.00, dengan melakukan Survai Plat Nomor Kendaraan. Data primer yang diperoleh berupa jumlah kendaraan yang berada di terminal sebelum survai dimulai serta

Jurnal APLIKASI: Media Informasi \& Komunikasi Aplikasi Teknik Sipil Terkini Halaman 45 
waktu dan jenis kendaraan masuk/keluar terminal selama waktu survai. Selain itu, data primer juga meliputi jumlah antrian serta waktu tundaan kendaraan yang melintas di ruas jalan depan terminal, yaitu jalan Pulo Gebang arah timur dari depan pintu terminal hingga persimpangan terdekat (gambar 2). Karakteristik parkir di dalam terminal serta antrian dan tundaan yang terjadi di ruas jalan depan terminal menjadi dasar penilaian efektifitas utilisasi terminal. Kapasitas statis parkir diperoleh dengan cara mem-plot langsung jumlah Satuan Ruang Parkir (SRP) yang mungkin pada denah terminal. Nilai SRP masing masing kendaraan ditentukan menggunakan dimensi ruang yang dibutuhkan untuk kendaraan parkir, termasuk ruang gang untuk sirkulasi.

Nilai satu SRP diambil dari jenis kendaraan terbanyak yang menggunakan terminal, dimana dalam kasus ini adalah Truk Besar. Dengan demikian, satu SRP dapat diisi oleh kendaraan yang lebih kecil lebih dari satu. Hasil perhitungan jumlah kendaraan berbagai ukuran yang dapat menggunakan satu SRP dan sisa lebar gang sirkulasi ditunjukkan pada Tabel 1. Dengan menggunakan persyaratan lebar gang sirkulasi minimal 6,5 m (Departemen Perhubungan Direktur Jenderal Perhubungan Darat, 1996), maka nilai SRP truk besar $=1$, truk kecil $=0,5$ dan mobil barang $=0,3$ hasil perhitungan (Tabel 1) dapat diterima.

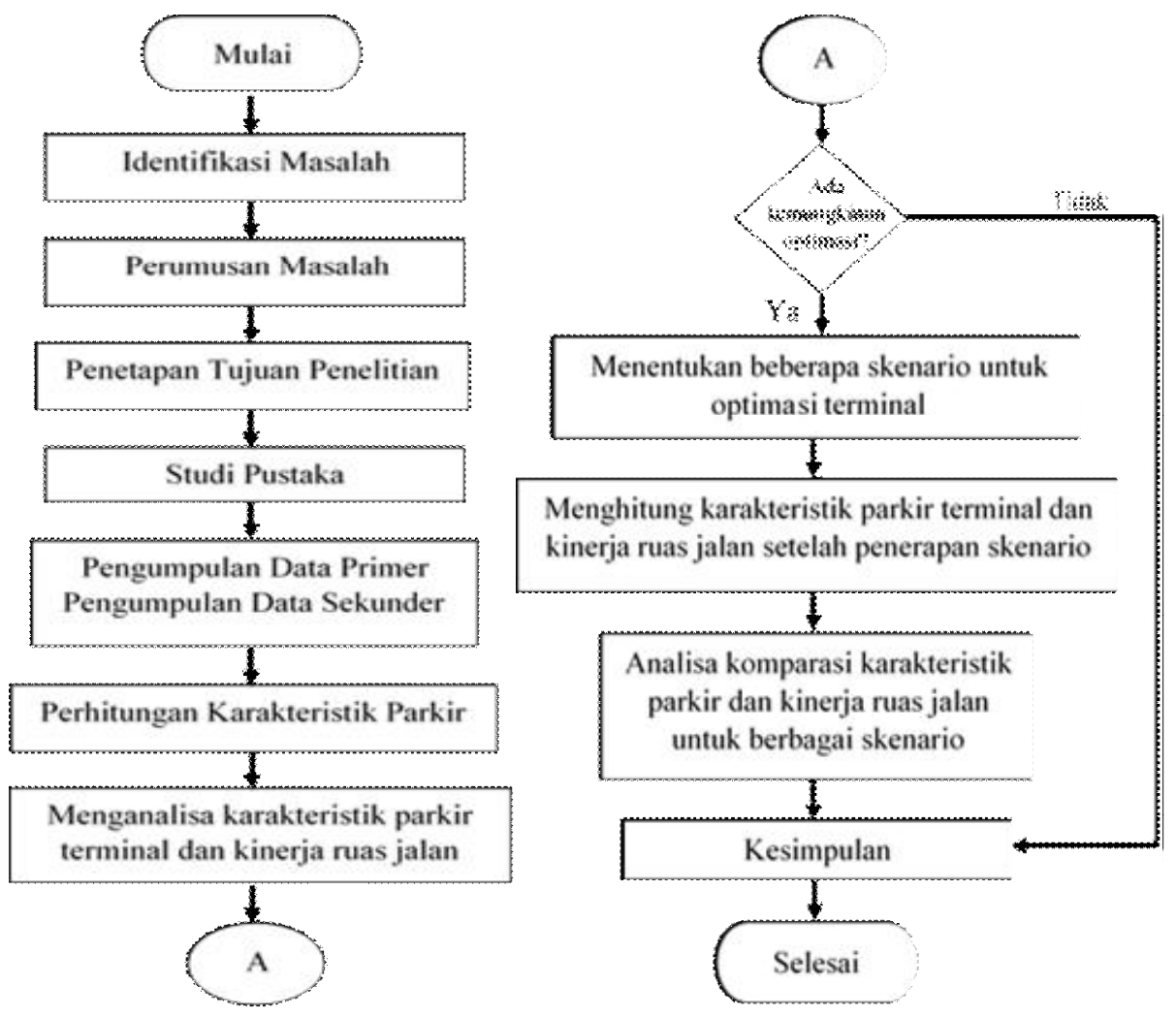

Gambar 1. Bagan alir penelitian

Halaman 46 Jurnal APLIKASI: Media Informasi \& Komunikasi Aplikasi Teknik Sipil Terkini 


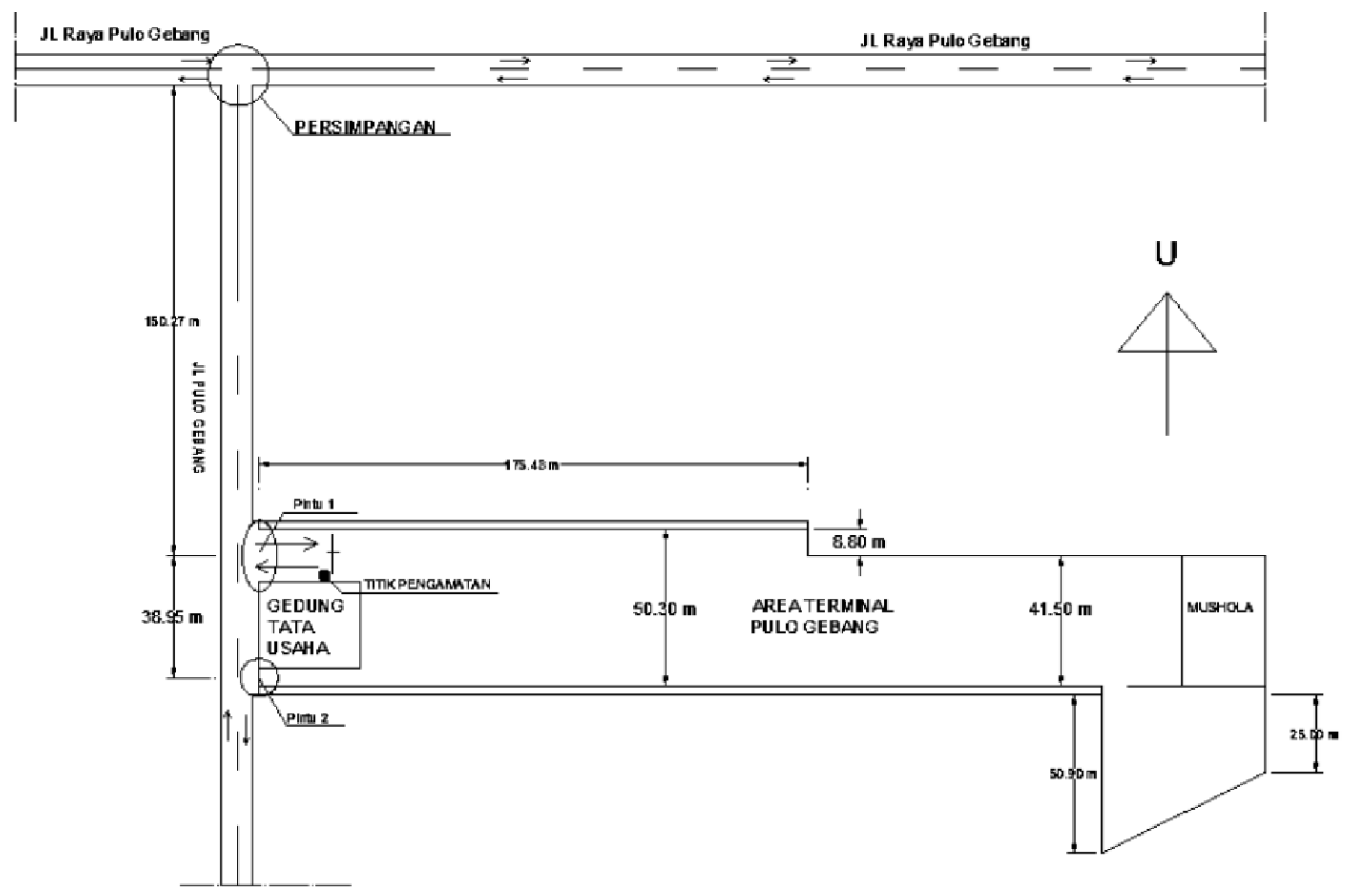

Gambar 2. Sketsa terminal angkutan barang Pulo Gebang

Berdasarkan nilai SRP (tabel 1), jumlah petak parkir adalah sebanyak 150 buah. Tetapi karena terdapat 23,5 SRP yang tidak bisa digunakan akibat terisi oleh kendaraan tidak layak pakai dan peralatan reparasi kendaraan, maka jumlah petak parkir menjadi 126,5 SRP. Selanjutnya, pada awal survai, di TAB Pulo Gebang telah terdapat 145 kendaraan dengan beberapa jenis seperti terlihat pada Tabel 2.

\section{Hasil dan Pembahasan}

Berdasarkan gambar 3 grafik pada hari Rabu dan kamis memiliki kecenderungan yang sama yaitu tinggi sekitar waktu subuh, menurun di saat pagi menjelang siang dan meningkat lagi pada siang dan malam. Pada hari Jumat flow in cenderung turun sementara flow out cenderung naik. Ini berarti aktifitas parkir terminal mulai berkurang dan pengguna terminal melakukan banyak aktifitas di luar terminal.

Pada Sabtu siang ketika flow in menjadi tinggi sementara flow out berbalik menurun drastis menandakan kendaraan mulai berpulangan untuk istirahat di dalam terminal memasuki hari Minggu. Pada hari Minggu, flow in dan flow out relatif stabil dan terjadi sepanjang hari tetapi dalam jumlah kecil.

Pada malam hari flow in dan flow out mulai berkurang hingga hanya ada aktifitas keluar masuk truk besar sepanjang Senin pagi. Flow in dan flow out pada hari Rabu didominasi oleh truk besar. Aktifitas truk besar ramai di hari kerja dan sepi di hari libur, sementara truk kecil dan mobil barang aktif di hari kerja dan hari libur.

Jurnal APLIKASI: Media Informasi \& Komunikasi Aplikasi Teknik Sipil Terkini Halaman 47 
Tabel 1. Nilai SRP beberapa jenis kendaraan objek penelitian

\begin{tabular}{lccccc}
\hline Jenis kendaraan & Nilai SRP & $\begin{array}{c}\text { Jumlah kendaraan } \\
\text { diperbolehkan } \\
\text { dalam satu SRP }\end{array}$ & $\begin{array}{c}\text { Panjang SRP } \\
(\mathrm{m})\end{array}$ & $\begin{array}{c}\text { Panjang kendaraan } \\
\text { untuk parkir dua } \\
\text { sisi (m) }\end{array}$ & $\begin{array}{c}\text { Lebar } \\
\text { gang } \\
\text { tersisa (m) }\end{array}$ \\
\hline $\begin{array}{l}\text { Truk Besar atau } \\
\text { truk trailer }\end{array}$ & 1 & 1 & 14,50 & 29,0 & 12,50 \\
$\begin{array}{l}\text { Truk Kecil (dump } \\
\text { truck) }\end{array}$ & 0,5 & 2 & 8,00 & 32,0 & 9,50 \\
$\begin{array}{l}\text { Mobil barang } \\
\text { (mobil box) }\end{array}$ & 0,3 & 3 & 5,5 & 33,0 & 8,50 \\
\hline
\end{tabular}

Tabel 2. Komposisi kendaraan yang terdapat di terminal sebelum survei

\begin{tabular}{|c|c|c|c|c|}
\hline \multirow{2}{*}{$\begin{array}{c}\text { Jenis } \\
\text { Kendaraan }\end{array}$} & \multicolumn{2}{|c|}{$\begin{array}{l}\text { Terlihat masih } \\
\text { berfungsi }\end{array}$} & \multicolumn{2}{|c|}{$\begin{array}{c}\text { Terlihat tidak } \\
\text { berfungsi }\end{array}$} \\
\hline & (Unit) & $\begin{array}{l}\text { Nilai } \\
\text { SRP }\end{array}$ & (Unit) & $\begin{array}{l}\text { Nilai } \\
\text { SRP }\end{array}$ \\
\hline $\begin{array}{l}\text { Truk } \\
\text { Kecil }\end{array}$ & 50 & 25 & 5 & 2.5 \\
\hline $\begin{array}{l}\text { Truk } \\
\text { Besar }\end{array}$ & 61 & 61 & 21 & 21 \\
\hline $\begin{array}{l}\text { Mobil } \\
\text { barang }\end{array}$ & 8 & 2.4 & 0 & 0 \\
\hline Total Ju & lah & 88.4 & & 23.5 \\
\hline
\end{tabular}

Akumulasi parkir rerata harian ditunjukkan pada Tabel 3. Nilai akumulasi parkir beberapa kali melewati garis kapasitas parkir yaitu pada hari Kamis, Jumat dan Minggu. Tetapi rerata akumulasi masing-masing hari tidak melewati kapasitas. Besarnya volume parkir masing-masing hari ditunjukkan pada Gambar 4. Nilai turn over per hari ditunjukkan pada Gambar 5.

Berdasarkan Gambar 6, nilai indeks parkir rerata di hari Rabu mencapai 77,7 $\%$, untuk kemudian naik menjadi sangat dekat dan bahkan beberapa kali melewati $100 \%$ pada hari Kamis dan Jumat, dan kemudian turun di hari Sabtu dan naik kembali pada hari Minggu dan Senin.

Penurunan nilai indeks parkir pada hari Sabtu ini kemungkinan dipicu oleh banyaknya truk yang melayani kegiatan di luar terminal yaitu kegiatan bongkar muat barang di pelabuhan ataupun di tempat lain untuk menutupi kekosongan pekerjaan pada hari Minggu.

Tabel 3. Tabulasi akumulasi parkir rerata harian dan keseluruhan

\begin{tabular}{ccccccc}
\hline Hari & Rabu & Kamis & Jumat & Sabtu & Minggu & Senin \\
\hline Tanggal & 30 & 31 & 1 & 2 & 3 & 4 \\
\hline Oktober 2013 & & November 2013 & \\
\hline $\begin{array}{c}\text { Akumulasi rerata } \\
\text { harian (SRP) }\end{array}$ & 98.2 & 120.4 & 121.8 & 96.7 & 120.6 & 123.8 \\
\hline
\end{tabular}

Halaman 48 Jurnal APLIKASI: Media Informasi \& Komunikasi Aplikasi Teknik Sipil Terkini 


\section{ISSN.1907-753X}
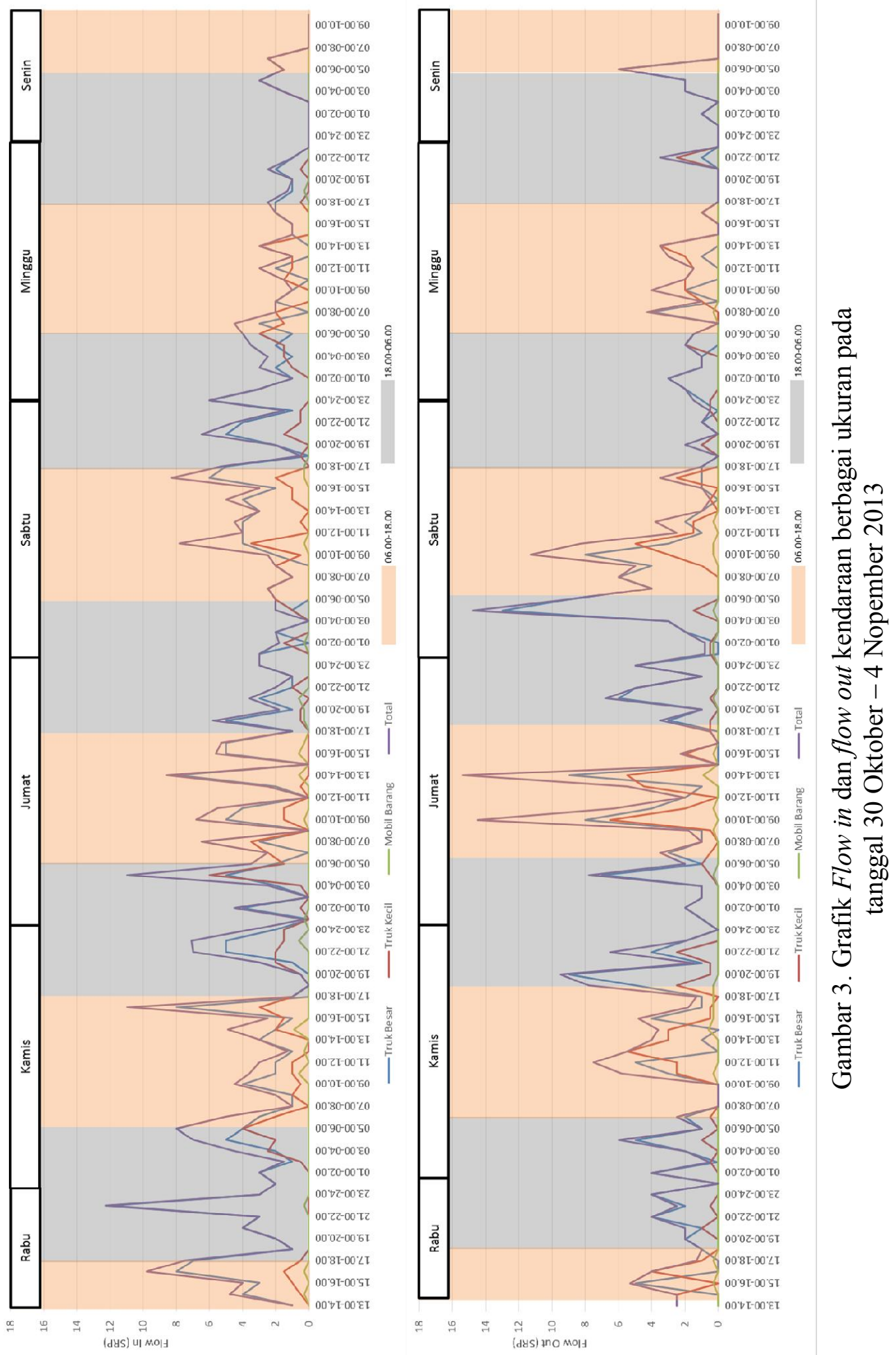

Jurnal APLIKASI: Media Informasi \& Komunikasi Aplikasi Teknik Sipil Terkini Halaman 49 


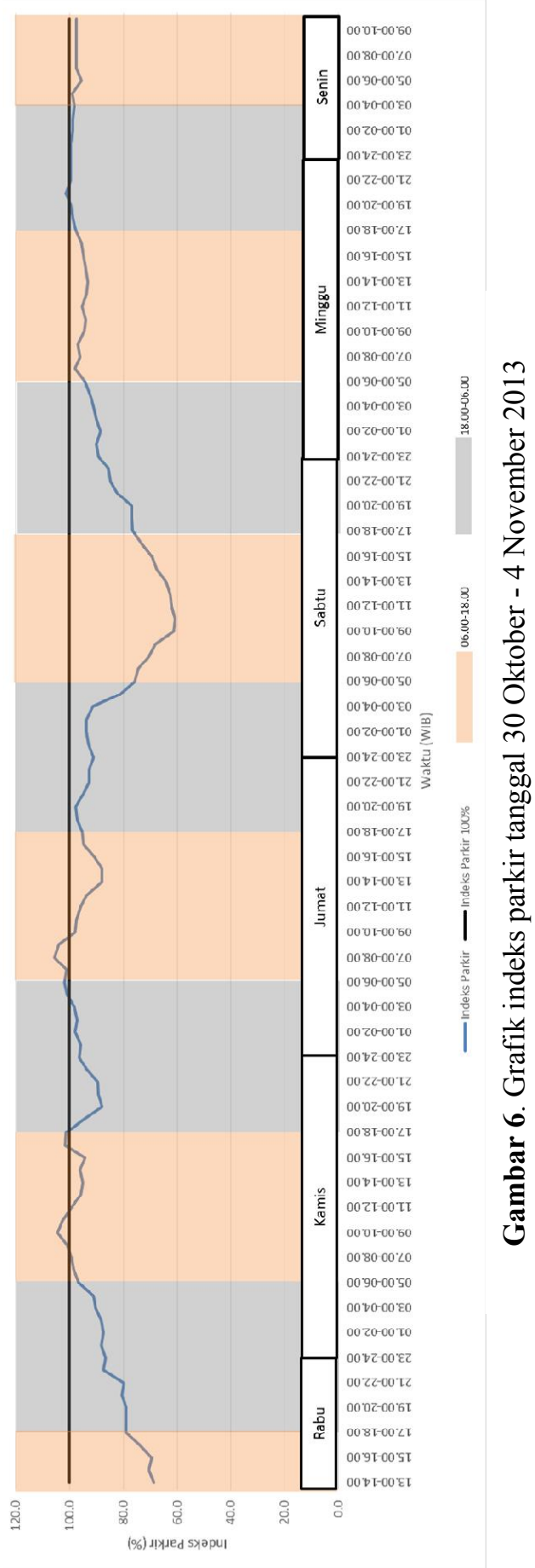


Hasil perhitungan durasi parkir ditunjukkan oleh Tabel 4. Rata - rata durasi parkir hari Sabtu lebih tinggi daripada hari sebelum dan sesudahnya.

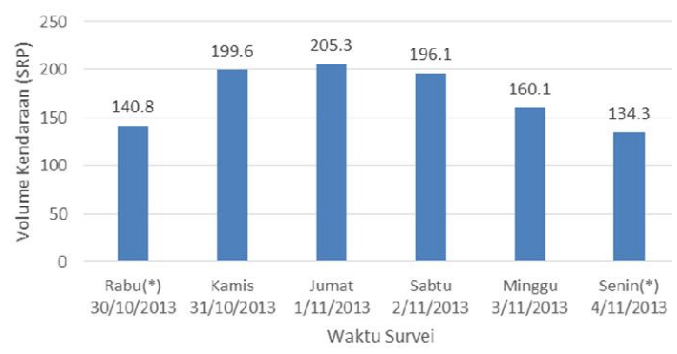

Gambar 4. Volume kendaraan keseluruhan 30 Oktober - 4 November (Survai dilakukan selama 11 jam)

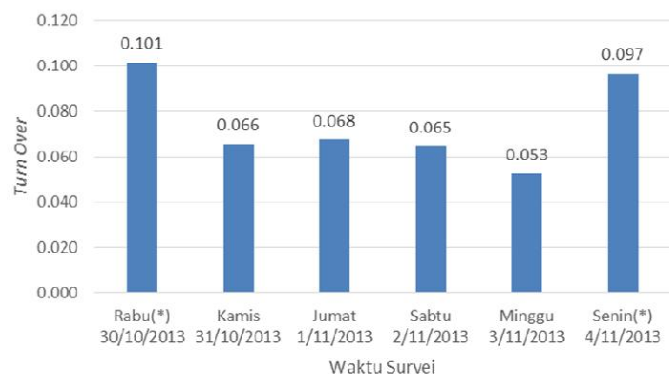

Gambar 5. Grafik nilai turn over tanggal 30 Oktober - 4 November pada masing masing hari survey (Survai dilukan selama 11 jam)

Ini disebabkan kendaraan pulang dari kegiatan bongkar muat dan akan beristirahat pada hari Minggu, dimana saat itu tidak ada kegiatan bongkar muat barang, terutama di pelabuhan.

Nilai Indeks Aktifitas Parkir terminal tanggal 30 Oktober-4 November 2013 ditunjukkan oleh Gambar 6.

Tabel 4. Nilai durasi pada masing - masing

\begin{tabular}{cccc} 
hari survei & & & \\
\hline Hari & Jumat & Sabtu & Minggu \\
\hline Tanggal & 1 & 2 & 3 \\
\cline { 2 - 4 } & \multicolumn{3}{c}{ November 2013} \\
\hline Durasi harian (jam) & 8,03 & 9,2 & 8,44 \\
\hline $\begin{array}{c}\text { Durasi Rerata Harian } \\
\text { (jam) }\end{array}$ & \multicolumn{3}{c}{8,56} \\
\hline
\end{tabular}

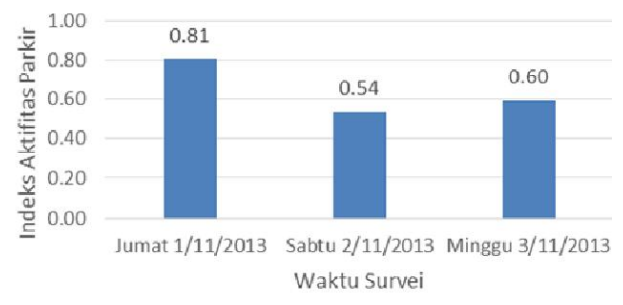

Gambar 6. Grafik nilai IAP tanggal 1 - 3 November 2013

Berdasarkan Gambar 6, terlihat bahwa IAP pada hari Jumat relatif jauh lebih tinggi dari hari Sabtu dan Minggu. Hal ini menunjukkan bahwa pada hari kerja TAB Pulo Gebang relatif lebih aktif dibanding hari Sabtu dan Minggu. Ini dapat disebabkan oleh akumulasi dan indeks parkir yang tinggi pada hari Jumat dibanding hari Sabtu dan juga kendaraan cepat berganti dengan durasi rata - rata yang lebih rendah. Sementara pada hari Minggu walaupun indeks parkirnya tinggi, tetapi nilai turn over yang terjadi rendah, sehingga aktifitas terminal menjadi rendah.

Kapasitas dinamis pada tanggal 1 - 3 November 2013 dapat dilihat pada Gambar 7.

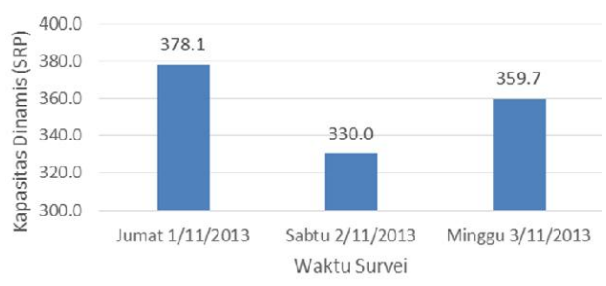

Gambar 7. Grafik kapasitas dinamis tanggal 1 - 3 November 2013

Berdasarkan Gambar 7, nilai kapasitas dinamis pada hari Jumat lebih tinggi dari hari lain, dan hari Sabtu memiliki kapasitas dinamis terendah. Grafik kapasitas dinamismemiliki pola yang mirip dengan IAP. Ini menunjukkan

Jurnal APLIKASI: Media Informasi \& Komunikasi Aplikasi Teknik Sipil Terkini Halaman 51 
kapasitas dinamis sesuai dengan IAP dalam menggambarkan keadaan terminal. Semakin aktif terminal, maka semakin tinggi kapasitas dinamisnya.

Nilai V/C Ratio pada tanggal $1-3$ November 2013 dapat dilihat pada Gambar 8.

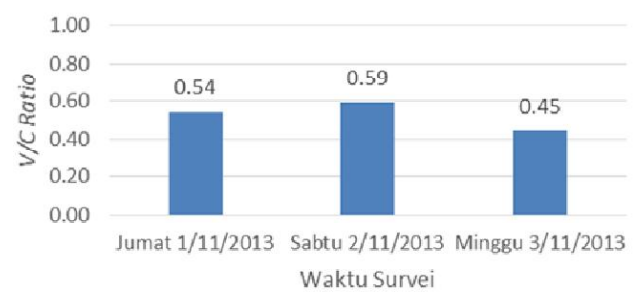

Gambar 8. Nilai V/C Ratio Tanggal 30 Oktober - 4 November 2013

Berdasarkan Gambar 8, nilai V/C Ratio relatif rendah yaitu tertinggi adalah 0,59 (pada hari Sabtu) dan terendah adalah 0,45 (pada hari Minggu). Hal ini berarti bahwa pada saat ini hanya 45 - $59 \%$ dari potensi terminal yang terutilisasi. Ini dapat disebabkan turn over yang rendah ataupun karena tidak ada aktifitas logistik yang dilakukan di luar terminal.

Nilai rerata tundaan beserta frekuensi kejadiannya serta jumlah antrian kendaraan setiap jam ditunjukkan pada Gambar 10 - 12. Antrian terpanjang yang terjadi adalah 11 satuan mobil penumpang.

Untuk mengevaluasi panjang antrian kendaraan, digunakan parameter panjang antrian maksimum kendaraan yang diperbolehkan, yaitu dihitung berdasarkan ukuran kendaraan penumpang standar yang ditunjukkan oleh Gambar 9 . Dengan ukuran standar tersebut antrian maksimum yang diizinkan pada jalan yang ditinjau dapat dihitung. Antrian diijinkan adalah

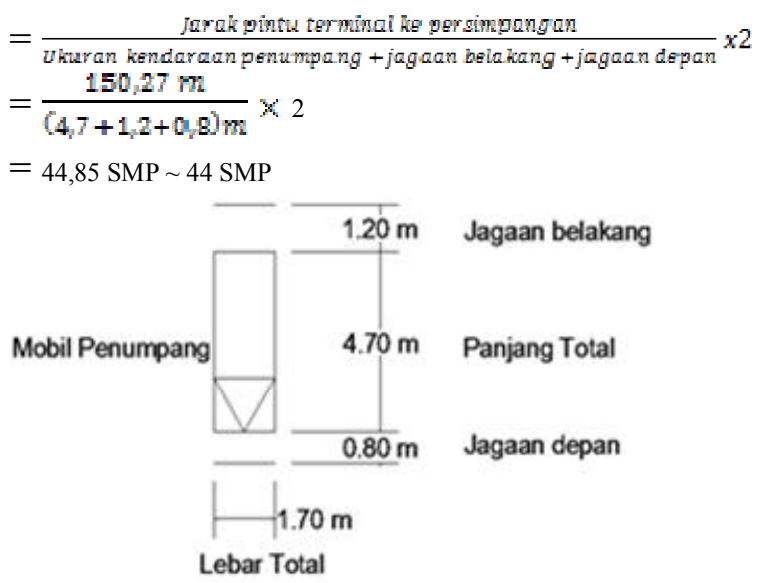

Gambar 9. Ukuran kendaraan penumpang untuk perhitungan antrian

Adapun nilai tundaan dievaluasi berdasarkan parameter Indeks Tingkat Pelayanan Lalu lintas. Dengan nilai rerata Tundaan 7 detik, diperoleh Indeks Tingkat Pelayanan lalu lintasnya termasuk kelas B atau relatif singkat (Hartom, 2005). Sementara dengan rerata Jumlah Antrian 2,46 3 SMP per jam $(6,82 \%)$ dapat dikatakan bahwa selama survai, antrian kendaraan masih jauh di bawah kapasitas kendaraan yang diperbolehkan antri (44 SMP).

\section{Analisa Perbaikan Sistem}

Berdasarkan besaran parameter-parameter parkir yang diperoleh, pada sebagian besar waktu survai terminal penuh dengan kendaraan dengan potensi terminal yang terutilisasi setengahnya. Sementara aktifitas terminal tidak memberikan dampak signifikan terhadap lalu lintas ruas jalan di depannya sehingga dapat dikatakan terminal tidak mengganggu ruas jalan dan terutilisasi dengan cukup efektif.

Halaman 52 Jurnal APLIKASI: Media Informasi \& Komunikasi Aplikasi Teknik Sipil Terkini 


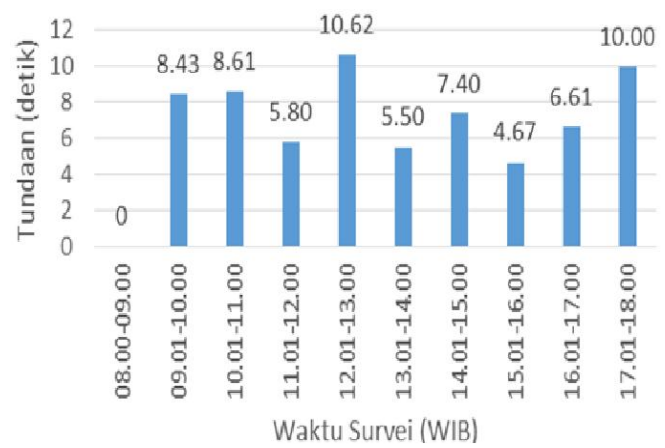

Gambar 10. Grafik rerata tundaan per jam

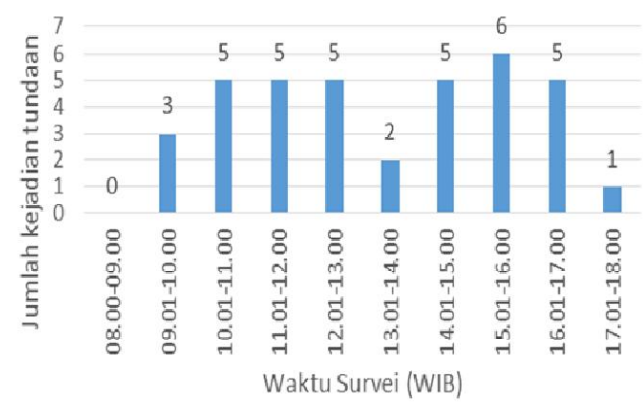

Gambar 11. Grafik jumlah kejadian tundaan per jam

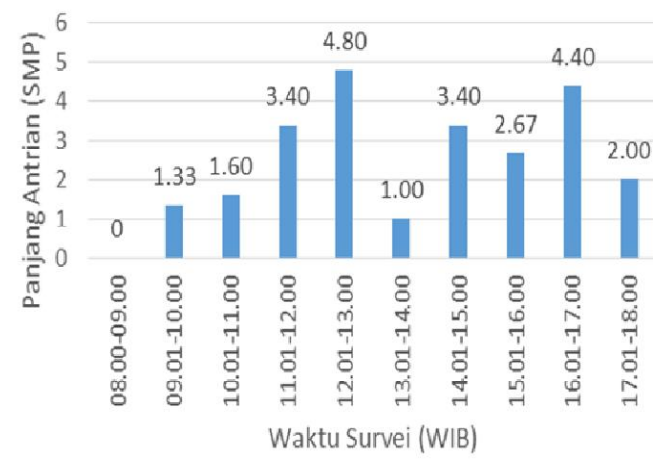

Gambar 12. Grafik rerata jumlah antrian akibat tundaan per jam

Meskipun demikian, terdapat beberapa hal yang dapat dioptimalkan pada terminal sebagai fasilitas parkir. Beberapa skenario perbaikan dianalisa untuk mengetahui dampaknya terhadap karakteristik parkir terminal Pulo Gebang.
Skenario 1: Tidak diijinkan adanya kendaraan tidak layak jalan Jika kendaraan rusak, kendaraan dalam perbaikan, dan tumpukan peralatan untuk reparasi kendaraan tidak menggunakan ruang parkir yang ada dan ruang ini diisi oleh kendaraan yang aktif, maka kinerja parkir dapat lebih optimal dan kapasitas statis bertambah dari 127,5 SRP menjadi 150 SRP. Perubahan parameter parkir dari skenario ini diperlihatkan pada Tabel 6 .

Skenario 2: Lahan di belakang terminal diperkeras

Lahan yang berada di belakang terminal saat ini belum diperkeras dan masih dipakai untuk menampung kendaraan umum yang tidak layak pakai seperti bajaj, angkot, dan metromini yang rusak. Lahan tersebut dapat diperkeras untuk menambah kapasitas statis terminal sebanyak 15 SRP seperti ditunjukkan oleh Gambar 13. Perubahan karakteristik parkir terminal ditunjukkan oleh Tabel 6.

Skenario 3: Pintu kedua terminal dioperasikan

Pintu 2 terminal (Lihat Gambar 14) saat ini tidak dioperasikan. Bila pintu kedua dioperasikan maka kapasitas antrian kendaraan dapat bertambah. Tetapi sebagai akibatnya adalah kapasitas statis terminal berkurang karena sebagian ruang digunakan untuk kendaraan masuk melalui pintu 2 (Lihat Gambar 15). Perubahan karakteristik parkir ditunjukkan pada Tabel 6.

Skenario 4: Tidak menggunakan sistem zona pada sistem penerimaan kendaraan

Jurnal APLIKASI: Media Informasi \& Komunikasi Aplikasi Teknik Sipil Terkini Halaman 53 
Pada saat ini sistem penggunaan lahan parkir masih menggunakan sistem sewa sehingga dapat terjadi parkir ganda dan mengurangi lebar gang sirkulasi walaupun nilai indeks parkir belum melewati $100 \%$. Skenario 4 dibuat dengan harapan kendaraan dapat parkir di petak parkir yang mana saja sehingga parkir ganda hanya terjadi ketika indeks parkir lebih dari $100 \%$.

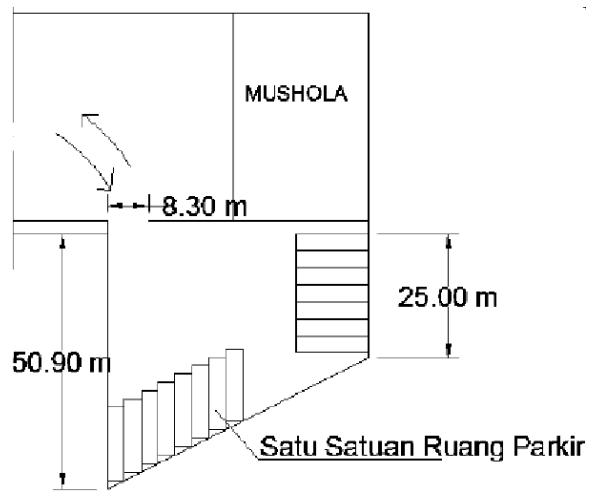

Gambar 13. Sketsa Plot Ruang Parkir Pada Lahan Di Sisi Belakang Terminal

\section{Skenario Gabungan}

Skenario gabungan merupakan skenario - skenario gabungan dari 4 skenario yang telah disebutkan diatas yaitu:

Tabel 5. Perbandingan parameter parkir terminal dengan berbagai skenario

\begin{tabular}{|c|c|c|c|c|c|c|c|}
\hline \multirow[b]{3}{*}{ Parameter } & \multirow[b]{3}{*}{ Do Nothing } & \multicolumn{2}{|c|}{ Skenario 1} & \multicolumn{2}{|c|}{ Skenario 2} & \multicolumn{2}{|c|}{ Skenario 3} \\
\hline & & \multirow[b]{2}{*}{ Perubahan } & \multirow[b]{2}{*}{$\%$ Perubahan } & \multicolumn{2}{|r|}{$\%$} & \multirow[b]{2}{*}{ Perubahan } & \multirow{2}{*}{$\begin{array}{c}\% \\
\text { Perubahan } \\
\end{array}$} \\
\hline & & & & Perubahan & Perubahan & & \\
\hline Kapasitas Statis (SRP) & 126.50 & 150.00 & 18.58 & 141.50 & 11.86 & 123.50 & -2.37 \\
\hline $\begin{array}{l}\text { Kapasitas Dinamis } \\
\text { (Kend/petak/jam) }\end{array}$ & 378.08 & 448.30 & 18.57 & 422.90 & 11.85 & 369.10 & -2.38 \\
\hline Indeks Parkir rerata $(\%)$ & 96.30 & 81.21 & -15.67 & 86.09 & -10.61 & 98.63 & 2.42 \\
\hline IAP & 0.81 & 0.58 & -28.88 & 0.65 & -20.08 & 0.85 & 4.92 \\
\hline V/C Ratio & 0.54 & 0.46 & -15.66 & 0.49 & -10.60 & 0.56 & 2.43 \\
\hline $\begin{array}{l}\text { Ruang antrian maksimum } \\
\text { diijinkan pada jalan depan } \\
\text { terminal }\end{array}$ & 44.00 & - & - & - & - & 56.00 & 27,27 \\
\hline Keterangan & & Peruba & an Sistem & Butu & biaya & Perubal & n sistem \\
\hline
\end{tabular}

a. Skenario 5 : Gabungan skenario 1 dan skenario 2 (dengan biaya)

b. Skenario 6 : Gabungan skenario 1 dan skenario 3 (tanpa biaya)

c. Skenario 7 : Gabungan skenario 2 dan skenario 3 (dengan biaya)

d. Skenario 8 : Gabungan skenario 1,2 dan 3 (dengan biaya)

Perubahan karakteristik parkir terminal dengan skenario gabungan diatas dapat dilihat pada Tabel 6 .

\section{Simpulan}

Operasi terminal telah cukup efektif dengan indeks parkir yang mendekati $100 \%$ di sebagian besar waktu survei walaupun $\mathrm{V} / \mathrm{C}$ ratio hanya berkisar antara 45 - 59\% yang menunjukkan potensi terminal yang terutilisasi masih setengahnya. Aktifitas kendaraan keluar masuk TAB Pulo Gebang tidak memberikan dampak lalu lintas yang signifikan terhadap arus lalu lintas di ruas jalan depan terminal.

Halaman 54 Jurnal APLIKASI: Media Informasi \& Komunikasi Aplikasi Teknik Sipil Terkini 


\section{ISSN.1907-753X}

Tabel 6. Perbandingan parameter parkir terminal dengan berbagai scenario (Lanjutan)

\begin{tabular}{|c|c|c|c|c|c|c|c|c|c|}
\hline \multirow{3}{*}{ Parameter } & \multirow{3}{*}{$\begin{array}{l}\text { Do } \\
\text { Nothin } \\
\quad \mathrm{g}\end{array}$} & \multicolumn{2}{|c|}{ Skenario 5} & \multicolumn{2}{|c|}{ Skenario 6} & \multicolumn{2}{|c|}{ Skenario 7} & \multicolumn{2}{|c|}{ Skenario 8} \\
\hline & & \multirow[b]{2}{*}{$\begin{array}{l}\text { Peruba } \\
\text { han }\end{array}$} & \multicolumn{2}{|l|}{$\%$} & \multirow{2}{*}{$\begin{array}{c}\% \\
\text { Peruba } \\
\text { han }\end{array}$} & \multicolumn{3}{|c|}{$\%$} & \multirow{2}{*}{$\begin{array}{c}\% \\
\text { Peruba } \\
\text { han }\end{array}$} \\
\hline & & & $\begin{array}{c}\text { Peruba } \\
\text { han }\end{array}$ & $\begin{array}{c}\text { Peruba } \\
\text { han }\end{array}$ & & $\begin{array}{c}\text { Peruba } \\
\text { han }\end{array}$ & $\begin{array}{c}\text { Peruba } \\
\text { han }\end{array}$ & $\begin{array}{c}\text { Peruba } \\
\text { han }\end{array}$ & \\
\hline Kapasitas Statis (SRP) & 126.50 & 165.00 & 30.43 & 147.00 & 16.21 & 138.50 & 9.49 & 162.00 & 28.06 \\
\hline \multicolumn{10}{|l|}{ Kapasitas Dinamis } \\
\hline (Kend/petak/jam) & 378.08 & 493.15 & 30.43 & 439.35 & 16.21 & 413.95 & 9.49 & 484.18 & 28.06 \\
\hline Indeks Parkir rerata $(\%)$ & 96.30 & 73.83 & -23.34 & 73.83 & -23.34 & 87.95 & -8.67 & 75.19 & -21.92 \\
\hline IAP & 0.81 & 0.48 & -41.22 & 0.53 & -34.02 & 0.68 & -16.58 & 0.49 & -39.03 \\
\hline V/C Ratio & 0.54 & 0.42 & -23.33 & 0.47 & -13.95 & 0.50 & -8.66 & 0.42 & -21.91 \\
\hline \multirow[t]{2}{*}{$\begin{array}{l}\text { Ruang antrian maksimum } \\
\text { diijinkan pada jalan depan } \\
\text { terminal }\end{array}$} & 44.00 & - & - & 56.00 & 27,27 & 56.00 & 27,27 & 56.00 & 27,27 \\
\hline & & \multicolumn{2}{|c|}{ Butuh biaya } & \multicolumn{2}{|c|}{ Perubahan sistem } & \multicolumn{2}{|c|}{$\begin{array}{c}\text { Ubah sistem dan } \\
\text { butuh biaya }\end{array}$} & \multicolumn{2}{|c|}{$\begin{array}{r}\text { Ubah sistem dan } \\
\text { butuh biaya }\end{array}$} \\
\hline
\end{tabular}

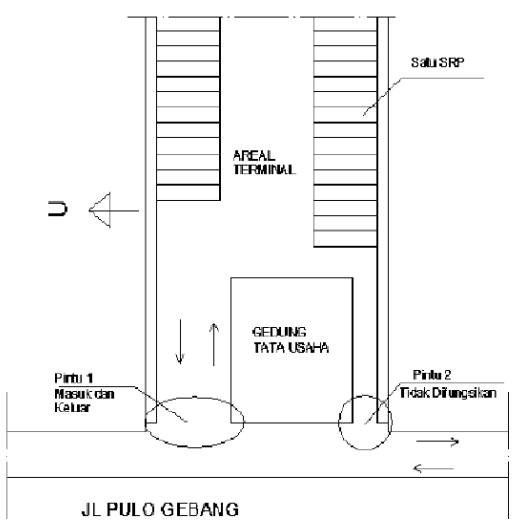

Pintu 2 Tidak Difungsikan

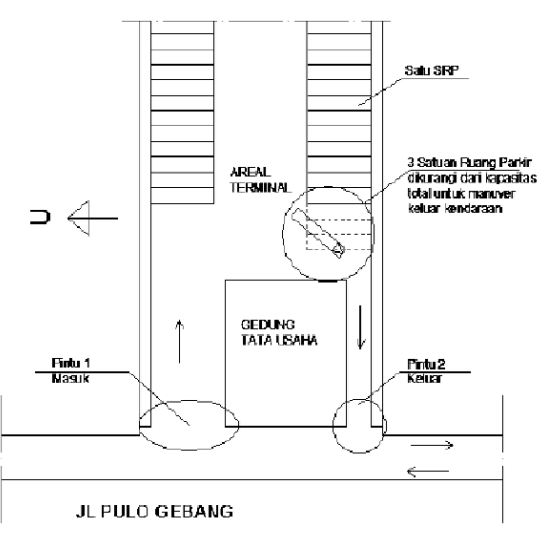

Pintu 2 Difungsikan

Gambar 14. Ilustrasi pengurangan SRP yang dibutuhkan untuk manuver kendaran masuk dari pintu 2
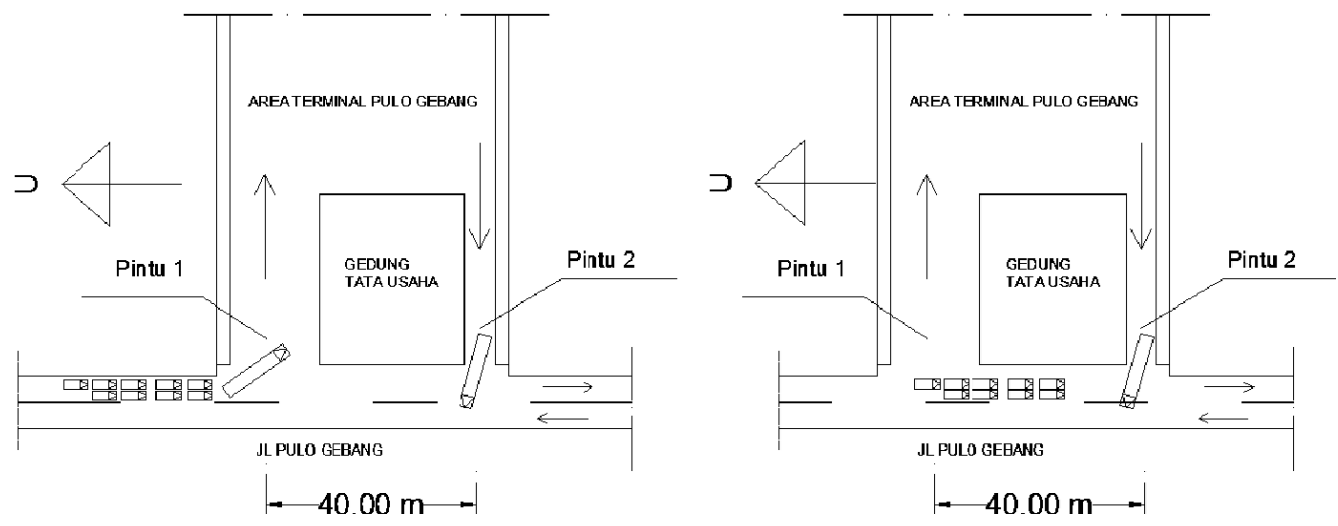

Gambar 15. Sketsa antrian pada pintu 1 (kiri) dan antrian pada pintu 2 (kanan) 
Tabel 7. Perubahan nilai parameter semua skenario

\begin{tabular}{|c|c|c|}
\hline Parameter & $\begin{array}{l}\text { Rentang } \\
\text { perubahan }\end{array}$ & $\begin{array}{l}\text { Rentang \% } \\
\text { perubahan } \\
(\%)\end{array}$ \\
\hline Kapasitas Statis & $\begin{array}{c}123,50- \\
165,00\end{array}$ & $\begin{array}{c}(-2,37)- \\
30,43\end{array}$ \\
\hline $\begin{array}{l}\text { Kapasitas } \\
\text { Dinamis }\end{array}$ & $\begin{array}{c}369,10- \\
493,15\end{array}$ & $\begin{array}{c}(-2,38)- \\
30,43\end{array}$ \\
\hline $\begin{array}{l}\text { Indeks Parkir } \\
\text { rerata }\end{array}$ & $\begin{array}{c}73,83- \\
98,63\end{array}$ & $\begin{array}{c}(-23,34)- \\
2,42\end{array}$ \\
\hline IAP & $0,48-0,85$ & $\begin{array}{c}(-41,22)- \\
4,92\end{array}$ \\
\hline V/C Ratio & $0,42-0,56$ & $\begin{array}{c}(-23,33)- \\
2,43\end{array}$ \\
\hline $\begin{array}{l}\text { Ruang antrian } \\
\text { maksimum } \\
\text { diijinkan pada } \\
\text { jalan depan } \\
\text { terminal }\end{array}$ & $44-56$ & $0-27,27$ \\
\hline
\end{tabular}

Terminal Pulo Gebang masih memiliki potensi yang dapat dikembangkan dengan menambah kapasitas statis dan panjang antrian kendaraan yang diizinkan. Setiap skenario memberikan rentang optimasi yang berbeda - beda seperti ditunjukkan pada tabel 6 .

\section{Daftar Pustaka}

Departemen Jenderal Bina Marga Perhubungan Pekerjaan Umum. 1996. Pedoman Teknis Perencanaan Fasilitas Parkir, DP.

Direktorat Jenderal Bina Marga Departemen Pekerjaan Umum. 1997. Tata Cara Perencanaan Geometrik Jalan antar Kota Jakarta, PU.

Hartom. 2005. Perencanaan Teknik Jalan (Geometrik) 1, Jakarta: UP Press.

Oppenlander J. C. and P. C. Box. 1976. Manual of Traffic
Engineering Studies, 4th Edition, Washington DC: Institute of Transportation Engineering Washington DC.

Priadi S., 2001. Pengukuran Indeks Aktifitas Parkir Dikaitkan dengan Tata Guna Lahan Sekitarnya.

Swamson H. A., 1994. "A New Measure of Parking-Activity Parking Activity Index," ITE Journal.

Tamin O. Z., 2000. Perencanaan dan Pemodelan Transportasi, Bandung: Penerbit ITB.

Tamin O. Z. and Nahdalina. 1998. "Analisis Dampak Lalu Lintas (Andall)," Jurnal Perencanaan Wilayah dan Kota, ITB.

Zakaria M., 2010. "Studi karakteristik parkir dan kebutuhan luas terminal Tegal sebagai terminal bus Tipe A."

Halaman 56 Jurnal APLIKASI: Media Informasi \& Komunikasi Aplikasi Teknik Sipil Terkini 